Marquette University

e-Publications@Marquette

Biological Sciences Faculty Research and

Publications

Biological Sciences, Department of

$11-2020$

\title{
Temporal Variability in Production is Not Consistently Affected by Global Change Drivers Across Herbaceous-Dominated Ecosystems
}

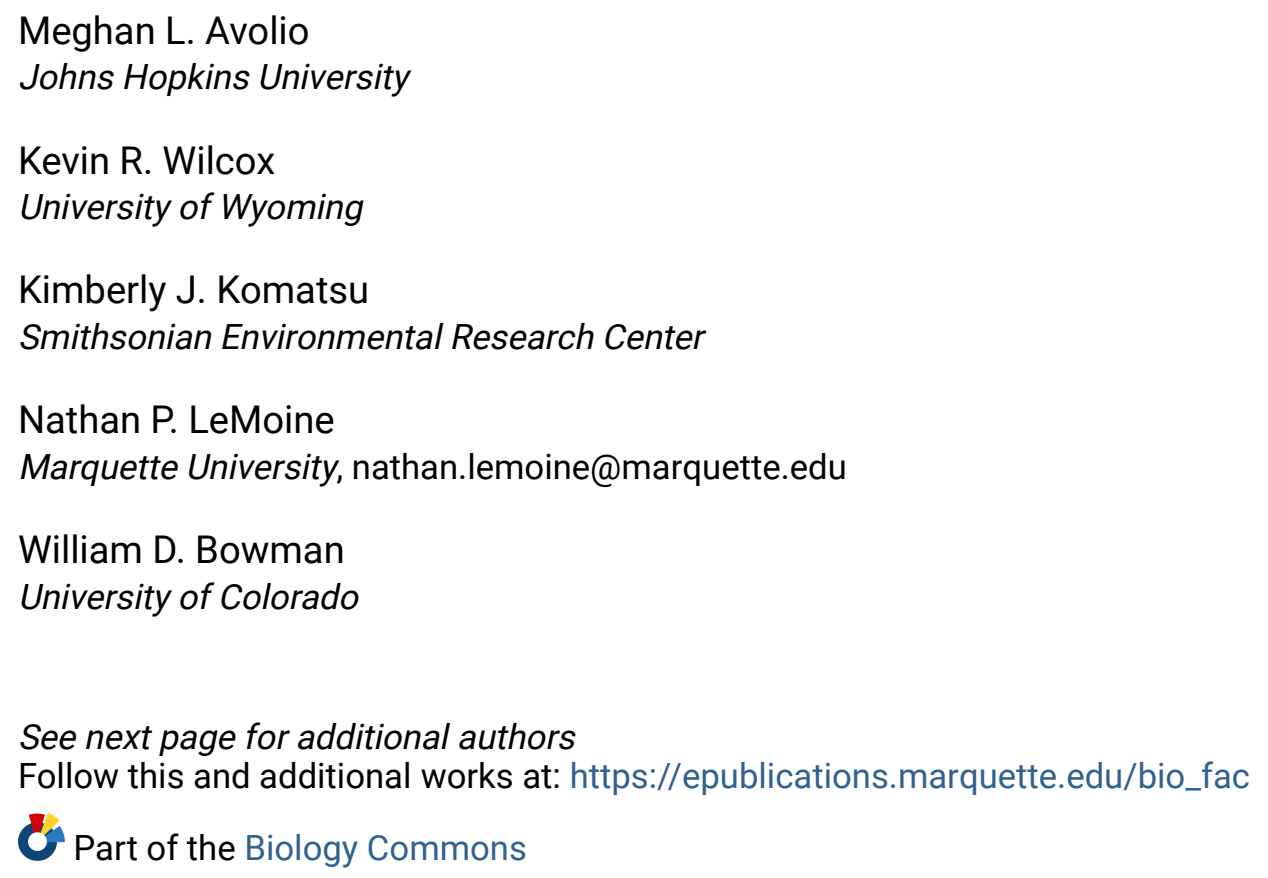

\section{Recommended Citation}

Avolio, Meghan L.; Wilcox, Kevin R.; Komatsu, Kimberly J.; LeMoine, Nathan P.; Bowman, William D.;

Collins, Scott L.; Knapp, Alan K.; Koerner, Sally E.; Smith, Melinda D.; Baer, Sara G.; Gross, Katherine; Isbell, Forest; McLaren, Jennie R.; Reich, Peter B.; Suding, Katherine; Suttle, K. Blake; Tilman, David; Xu, Zhuwen; and Yu, Qiang, "Temporal Variability in Production is Not Consistently Affected by Global Change Drivers Across Herbaceous-Dominated Ecosystems" (2020). Biological Sciences Faculty Research and Publications. 819.

https://epublications.marquette.edu/bio_fac/819 


\section{Authors}

Meghan L. Avolio, Kevin R. Wilcox, Kimberly J. Komatsu, Nathan P. LeMoine, William D. Bowman, Scott L. Collins, Alan K. Knapp, Sally E. Koerner, Melinda D. Smith, Sara G. Baer, Katherine Gross, Forest Isbell, Jennie R. McLaren, Peter B. Reich, Katherine Suding, K. Blake Suttle, David Tilman, Zhuwen Xu, and Qiang $\mathrm{Yu}$ 
Marquette University

e-Publications@Marquette

\section{Biological Sciences Faculty Research and Publications/College of Arts and Sciences}

This paper is NOT THE PUBLISHED VERSION.

Access the published version via the link in the citation below.

Oecologia, Vol. 194 (November 1, 2020): 735-744. DOI. This article is C Springer and permission has been granted for this version to appear in e-Publications@Marquette. Springer does not grant permission for this article to be further copied/distributed or hosted elsewhere without the express permission from Springer.

\section{Temporal variability in production is not consistently affected by global change drivers across herbaceous-dominated ecosystems}

\section{Meghan L. Avolio}

Department of Earth and Planetary Sciences, Johns Hopkins University, 3400 N. Charles St., Baltimore, MD

Kevin R. Wilcox

Department of Ecosystem Science and Management, University of Wyoming, Laramie, WY

Kimberly J. Komatsu

Smithsonian Environmental Research Center, 647 Contees Wharf Road, Edgewater, MD

Nathan Lemoine

Department of Biological Sciences, Marquette University, Milwaukee, WI

Department of Zoology, Milwaukee Public Museum, Milwaukee, WI

William D. Bowman

Department of Ecology and Evolutionary Biology, University of Colorado, Boulder, CO 


\section{Scott L. Collins}

Department of Biology, University of New Mexico, Albuquerque, NM

Alan K. Knapp

Department of Biology, Colorado State University, Fort Collins, CO

Graduate Degree Program in Ecology, Colorado State University, Fort Collins, CO

\section{Sally E. Koerner}

Department of Biology, University of North Carolina Greensboro, Greensboro, NC

Melinda D. Smith

Department of Biology, Colorado State University, Fort Collins, CO

Graduate Degree Program in Ecology, Colorado State University, Fort Collins, CO

Sara G. Baer

Kansas Biological Survey and Department of Ecology and Evolutionary Biology, University of Kansas, Lawrence, KS

\section{Katherine L. Gross}

WK Kellogg Biological Station and Graduate Program in Ecology, Evolutionary Biology and Behavior, Michigan State University, Hickory Corners, MI

Forest Isbell

Department of Ecology, Evolution and Behavior, University of Minnesota, Saint Paul, MN

\section{Jennie McLaren}

Department of Biological Sciences, University of Texas at El Paso, El Paso, TX

Peter B. Reich

Department of Forest Resources, University of Minnesota, Saint Paul, MN

Hawkesbury Institute for the Environment, Western Sydney University, Penrith, NSW, Australia

Katharine N. Suding

Department of Ecology and Evolutionary Biology, University of Colorado, Boulder, CO

K. Blake Suttle

Angelo Coast Range Reserve, Branscomb, CA

David Tilman

Department of Ecology, Evolution and Behavior, University of Minnesota, Saint Paul, MN

\section{Zhuwen Xu}

Key Laboratory of Grassland Ecology, School of Ecology and Environment, Inner Mongolia University, Hohhot, 010021, China

\section{Qiang Yu}

National Hulunber Grassland Ecosystem Observation and Research Station, Institute of Agricultural Resources and Regional Planning, Chinese Academy of Agricultural Sciences, Beijing, 100081, China 


\section{Abstract}

Understanding how global change drivers (GCDs) affect aboveground net primary production (ANPP) through time is essential to predicting the reliability and maintenance of ecosystem function and services in the future. While GCDs, such as drought, warming and elevated nutrients, are known to affect mean ANPP, less is known about how they affect inter-annual variability in ANPP. We examined 27 global change experiments located in 11 different herbaceous ecosystems that varied in both abiotic and biotic conditions, to investigate changes in the mean and temporal variability of ANPP (measured as the coefficient of variation) in response to different GCD manipulations, including resource additions, warming, and irrigation. From this comprehensive data synthesis, we found that GCD treatments increased mean ANPP. However, GCD manipulations both increased and decreased temporal variability of ANPP (24\% of comparisons), with no net effect overall. These inconsistent effects on temporal variation in ANPP can, in part, be attributed to site characteristics, such as mean annual precipitation and temperature as well as plant community evenness. For example, decreases in temporal variability in ANPP with the GCD treatments occurred in wetter and warmer sites with lower plant community evenness. Further, the addition of several nutrients simultaneously increased the sensitivity of ANPP to interannual variation in precipitation. Based on this analysis, we expect that GCDs will likely affect the magnitude more than the reliability over time of ecosystem production in the future.

\section{Introduction}

Aboveground net primary production (ANPP) is the principal energy source for higher trophic levels, and production of upper trophic levels depends on the amount and variability of ANPP over time (McNaughton et al. 1989). Therefore, understanding what regulates variation in ANPP through time is critical for predicting longterm patterns of ecosystem functioning and services (Daily et al. 2009). As such, identifying drivers of ANPP and its variability through time has been a central goal in ecology for decades (Clements 1916; MacArthur 1955; May 1973). This goal takes on greater urgency with predicted global change as ecologists seek to forecast future ecosystem function (Clark et al. 2001).

Global change drivers (GCDs), such as land-use change, nitrogen deposition, elevated $\mathrm{CO}_{2}$ and more extreme climate regimes (Vitousek et al. 1997; Sala et al. 2000), can directly impact average and temporal variability of ANPP in herbaceous systems (Morgan et al. 2004; Ladwig et al. 2012; Natali et al. 2012; Tilman et al. 2012; Borer et al. 2014; Avolio et al. 2014; Hautier et al. 2015; Koerner et al. 2016; Wilcox et al. 2016; Song et al. 2019). Depending on the type and direction of GCD, ANPP may increase, decrease, or exhibit no change (Smith et al. 2015; Andresen et al. 2016; Song et al. 2019). Generally, GCDs that increase limiting resources, such as $\mathrm{CO}_{2}$, nutrient, and water additions, increase ANPP (Morgan et al. 2004; Nowak et al. 2004; Wu et al. 2011; Wilcox et al. 2017; Song et al. 2019) as do warmer temperatures, particularly in cold environments (Rustad et al. 2001; Wu et al. 2011). In contrast, GCDs that decrease resources, such as drought, reduce ANPP (Wu et al. 2011; Hoover et al. 2014; Song et al. 2019). A recent meta-analysis notes that in addition to studying GCDs in isolation, there is a need for more research of the interacting effects of GCDs on ANPP (Song et al. 2019). GCDs also can affect temporal variability of ANPP, which may be correlated with how a particular GCD impacts mean ANPP. For example, nutrient additions have been shown to increase inter-annual variability of ANPP (Hautier et al. 2015; Koerner et al. 2016), whereas water additions decrease inter-annual variability of ANPP (Knapp et al. 2001). It remains unclear, however, whether these results are generalizable across ecosystems, especially to those where ANPP is more limited by water, less limited by nutrients, or both. Meta-analyses of temporal variability of ANPP are limited because multiple years of data are needed. Factors limiting productivity vary across ecosystems (Schimel et al. 1997; Knapp et al. 2017), and accordingly the effects of GCDs on mean and temporal variability of ANPP may vary. Thus, synthesis is needed to infer generality (Ives and Carpenter 2007). 
Generally, temporal dynamics of ANPP in herbaceous systems depend upon annual precipitation (Sala et al. 1988, 1996, 2012; Knapp and Smith 2001; La Pierre et al. 2016; Knapp et al. 2017; Rudgers et al. 2018). Here, we define temporal dynamics as interannual variation. Sensitivity of ANPP to precipitation (i.e., change in ANPP per $\mathrm{mm}$ change in rainfall) varies with mean annual precipitation (MAP). For example, drier sites are more sensitive to inter-annual variability in precipitation than wetter sites (Huxman et al. 2004; Sala et al. 2012). Varying sensitivity across a gradient of water limitation has been attributed to co-limitation by nutrients in more mesic sites (Huxman et al. 2004), which has been supported experimentally (Ladwig et al. 2012). Thus, certain global change drivers (GCDs), such as increased nutrient inputs, may increase the sensitivity of ANPP to precipitation in mesic ecosystems if nutrient limitation becomes alleviated, but responses may be less in more xeric ecosystems (Noy-Meir 1973; Collins et al. 2014). Consequently, altered sensitivity to precipitation under GCDs would modulate the degree of temporal variability of ANPP across ecosystems.

In addition to interannual precipitation variability, a number of other biotic and abiotic factors also affect temporal variability in ANPP (Niu et al. 2017a, b). Many studies have shown that biodiversity affects variation in ANPP (Hector et al. 2010; Isbell et al. 2015). Across grasslands globally, temporal variability of ANPP decreases as species richness increases (Tilman and Downing 1994; Hector et al. 1999, 2010; Tilman et al. 2006; Gross et al. 2014; Hautier et al. 2014, 2015; Isbell et al. 2015). Moreover, Seddon et al. (2016) showed that global productivity is also limited by sunlight and temperature. Because many factors impact ANPP, we need to better understand how GCDs will affect the mean and variability of ANPP in the future across a broad array of ecosystems.

We performed a data synthesis using the CoRRE (Community Responses to Resource Experiments; corredata.weebly.com) database to investigate whether different global change manipulations affect both mean and temporal variability of ANPP in herbaceous ecosystems. The CoRRE database is a collection of multi-year GCD experiments where at least one resource is experimentally manipulated. Manipulations include increases in water and $\mathrm{CO}_{2}$, single or multiple resources (e.g., nitrogen, phosphorus) as well as changes in temperature (heat), precipitation regimes, and altered disturbance regimes, such as burning and tilling. While it is informative to study effects of different GCDs in isolation, their interactive effects can produce non-intuitive responses (Elser et al. 2007; Darling and Côté 2008; Leuzinger et al. 2011; Morgan et al. 2011). To reveal general patterns of the effects of GCD manipulations on ecosystem productivity, we examined both changes in the mean ANPP over the course of each experiment and temporal variability of ANPP as measured by coefficient of variation, and investigated what may be affecting patterns of GCD treatment effects on temporal variability of ANPP. Specifically, we hypothesized: (1) that GCD treatments that alleviate a limiting resource will increase mean and temporal variability in ANPP, (2) that GCD treatment effects on temporal variability of ANPP will vary depending on abiotic (e.g., temperature, precipitation) and biotic (i.e., richness, evenness) site characteristics, where drier sites will become more variable with GCDs and sites with more plant species will be less variable with GCDs, and (3) that nutrient additions will increase sensitivity to precipitation.

\section{Methods}

\section{ANPP data}

To be included in the CoRRE database, an experiment had to manipulate at least one plant resource, but not all treatments in the experiment had to be resource manipulations; thus, we have treatments, such as warming and herbivory. All datasets include a measure of abundance for each species recorded in a plot, and $58 \%$ also include ANPP data. We used a subset of the CoRRE datasets that had six or more years of ANPP data. To date, analyses of GCD effects on variability of ANPP are limited to one site, Cedar Creek LTER (Hautier et al. 2014) or span several sites but are only three years in duration using data from the nutrient network (Hautier et al. 2015). Our data synthesis is both long-term and includes 11 sites to provide necessary insight into the effects of GCDs 
on ANPP and variability of ANPP. This resulted in 27 datasets at 11 sites and 95 treatment-to-control comparisons (see Table S1 in Supporting Information for details) including 13 different GCD treatments that were included in 2 to 35 experiments each (Table 1). Importantly, the overall effect of these treatments on ANPP varied over time allowing us to examine temporal dynamics of ANPP (ESM Figure S1).

Table 1 Global change driver (GCD) treatments used across the 27 experiments included in this analysis

\begin{tabular}{|c|c|c|c|}
\hline Treatment & $\begin{array}{l}\text { Number of } \\
\text { experiments }\end{array}$ & $\begin{array}{l}\text { Number of } \\
\text { sites }\end{array}$ & Notes \\
\hline $\mathrm{CO}_{2}$ & 5 & 2 & \\
\hline Water* & 7 & 5 & All experiments were water additions \\
\hline Nitrogen* & 11 & 8 & \\
\hline Phosphorus & 5 & 2 & \\
\hline Heat & 4 & 3 & \\
\hline Non-Resource & 7 & 4 & $\begin{array}{l}\text { Includes fungicide, soil depth, altered } \\
\text { precipitation patterns, burning, and tilling }\end{array}$ \\
\hline Nitrogen $+\mathrm{CO} 2 * *$ & 2 & 2 & \\
\hline Nitrogen + Water** & 3 & 3 & \\
\hline Nitrogen + Heat** & 2 & 2 & \\
\hline Water + Heat** & 2 & 2 & \\
\hline Multiple Nutrients* & 33 & 5 & $\begin{array}{l}\text { Includes all treatments with more than one } \\
\text { nutrient (e.g. } N+P, N+P+K)\end{array}$ \\
\hline Nitrogen + Water + Heat** & 2 & 2 & \\
\hline Nutrients + Non-Resource & 12 & 4 & \\
\hline
\end{tabular}

We note the number of experiments in which that treatment occurred, which is the sample size for each individual GCD treatment in the analyses, and the number of sites where a treatment was manipulated. An asterisk denotes those treatments that were performed at five or more locations. Two asterisks denote those treatments were included in interacting drivers treatment category, which has 11 control-treatment comparisons. In total there were 95 control-treatment comparisons. See Table S1 for more details on the treatments and experiments

Stability (mean/standard deviation) and coefficient of variability (CV, standard deviation/mean) are both measures of the temporal variability of ANPP (Knapp and Smith 2001; Hautier et al. 2015). Stability is roughly the inverse of variability (Lehman and Tilman 2000) and we will refer to both as measures of variability. Here, we used CV as our measure of variability, but results using stability were qualitatively similar. For each plot in an experiment, we calculated the mean $\left(\mathrm{ANPP}_{\mu}\right)$ and standard deviation (ANPP $\mathrm{SD}_{\text {; }}$ shown in ESM Figure S2) of ANPP over the number years of the experiment, and from this calculated the CV $\left(A N P P C V=A N P P_{S D} / A N P P_{\mu}\right)$ for each replicate in an experiment. We used these values to calculate percent difference between the treatment and control plots. First, we averaged $\mathrm{ANPP}_{\mu}$ and $\mathrm{ANPP} c \mathrm{v}$ of all replicates in a treatment or control and then calculated percent difference as ((treatment-control)/control)*100. Percent difference values near 0 indicate no change, positive values indicate that the treatment had increased the response variable relative the controls, and negative values indicate the treatments had reduced the response variable relative to the controls.

\section{Site abiotic and biotic descriptors}

Because precipitation data were not included in the CoRRE database, we obtained local annual precipitation data for each of the experimental sites for each year of an experiment. For the five sites where there was a local station (ANG, CDR, KNZ, MAERC, NWT), we used the Global Historical Climatology Network to access daily observations from the closest weather station using the rnoaa R library (Chamberlain 2018). For Global 
Historical Climatology Network data, we excluded years missing more than $10 \%$ of the data. For one site (KLU), we used monthly precipitation data from Environment Canada, as this datum was not in Global Historical Climatology Network. For three sites that did not have local weather stations with reliable data, we used data collected from weather stations located at the site (SEV: hourly data; SERC: a combination of hourly and daily data; KBS: daily data). For two sites (DL and IMGERS), we could only obtain yearly totals that were provided by site investigators. In addition, mean annual precipitation (MAP) and mean annual temperature (MAT) were obtained from the WorldCLIM database (https://www.worldclim.org) for all sites.

To calculate evenness at a site, we used the average evenness of control plots over all time points using the community_structure() function in the library("codyn") R package (Hallett et al. 2019). We used Evar as our measure of evenness (Smith and Wilson 1996). To remove bias in sampling area and effort, we calculated rarefied species richness using poolaccum() function in the vegan package (Oksanen et al. 2019) in R and drew estimates for the lowest sampling effort in our database across all sites. See Komatsu et al. (2019) for more details.

\section{Statistical analyses}

All statistical analyses were conducted in R version 3.6.0 (R Core Team 2019) with an alpha set to 0.05 and all code can be found at the github repository mavolio/ANPP_Variability_Oecologia. Treatment was not included as a fixed effect in our models because treatment types were not well replicated across experiments (Table 1). Multi-nutrient additions, nitrogen addition, water, and interacting drivers (e.g. nitrogen and water addition) were well-replicated across sites, so we examined their effects separately, otherwise all treatments were grouped together.

To assess how GCDs affect ANPP and the temporal variability of ANPP, we performed two complementary analyses. First, for each treatment in an experiment, we performed two-tailed $t$ tests between control and treated replicates to determine whether mean or temporal variability of ANPP differed and then tallied these results. Next, to assess the magnitude of treatment effects, we performed one-tailed $t$ tests of the percent difference between treatment and controls for mean and temporal variability of ANPP to see if they differed from zero across all experimental treatments as well as for each of the three well-replicated treatment types and interacting drivers.

We performed three additional analyses to further investigate GCD treatment effects on temporal variability of ANPP. We examined the effect of site characteristics on GCD treatment effects on temporal variability of ANPP. To do so, we used Pearson's correlations and stepwise multiple regression [stepAIC() function in the library("MASS") package (Venables and Ripley 2002)] to investigate which site characteristics (MAT, MAP, rarefied site species richness, and site evenness) correlated with percent difference temporal variability of ANPP. Partial $R^{2}$ values were determined with the rsq.partial() function in the library( "rsq") package (Zhang 2018). Next, we determined if GCD treatments affected the sensitivity of ANPP to environmental variation. We calculated the difference (treatment control) of the slopes from a linear regression between yearly ANPP and precipitation for each treatment in each experiment. A positive number indicated that treatment plots are more responsive to precipitation than the control plots. To test whether each GCD treatment affected ANPP sensitivity to precipitation, we ran a one-tailed $t$ test to determine if the change in sensitivity (difference in slopes) differed from zero.

\section{Results}

\section{Do GCDs affect mean and temporal variability of ANPP?}

In $56 \%$ of the GCD treatments, ANPP of treated plots was not significantly different than controls (Fig. 1a), and for $76 \%$ of GCD treatments, temporal variability of ANPP of treated plots did not differ from controls (Fig. 1b). 
When treatment differed from control, mean ANPP increased in 38 out of 42 comparisons (Fig. 1a), whereas, temporal variability of ANPP increased in eight and decreased in 15 comparisons (Fig. 1b). Multiple nutrients and water addition increased ANPP more often than nitrogen alone and when several interacting drivers were simultaneously manipulated (Fig. 1a). In $>75 \%$ of comparisons, multiple nutrients, water and nitrogen addition and interacting drivers had no effect on the temporal variability of ANPP (Fig. 1b).
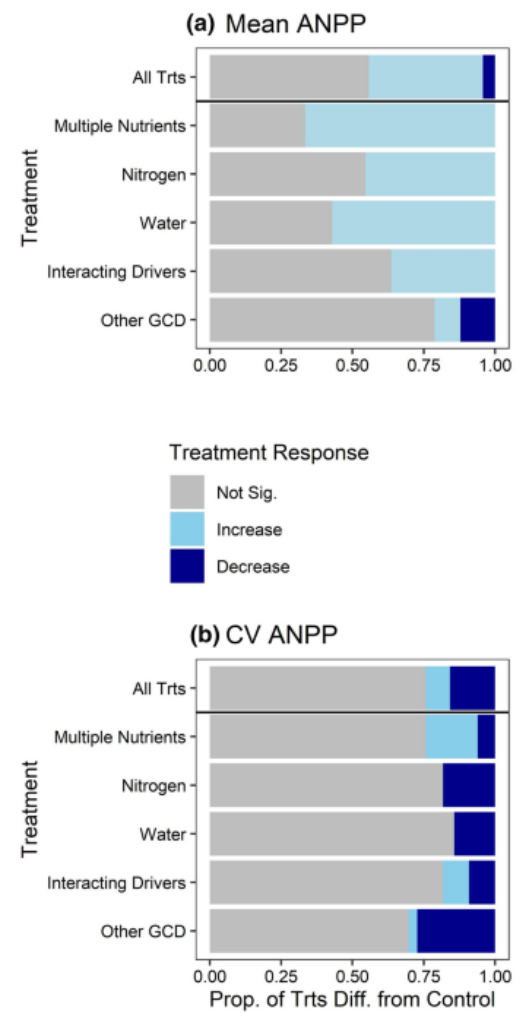

(c) Mean ANPP

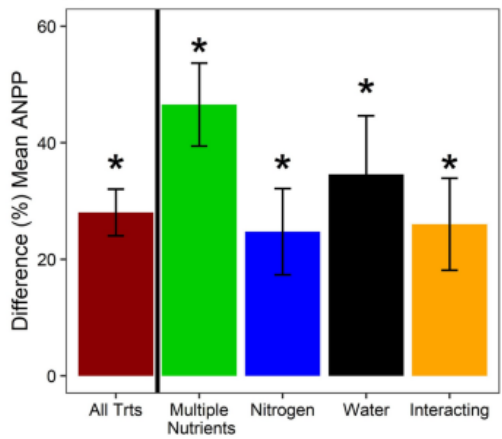

(d) CV ANPP

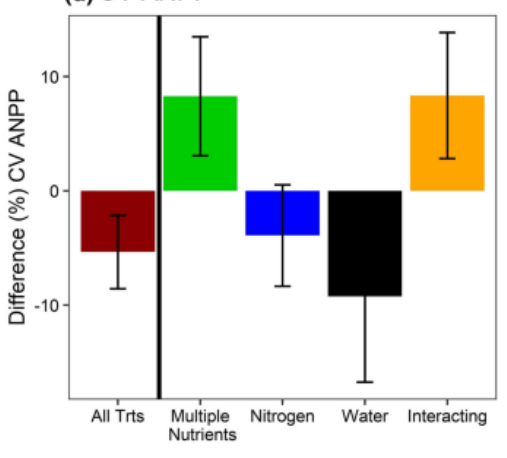

Fig. 1 Proportion of treatments with no change (based on a $t$ test between control and treated plots), an increase, or decrease in a) mean ANPP and b) temporal variability (CV) of ANPP. Percent difference between treated and control plots for $c$ ) mean ANPP and d) temporal variability (CV) of ANPP. Shown are means \pm S.E. An asterisk denotes significant difference from zero at $p<0.05 . \mathrm{n}=95$ for all treatments, 33 for multiple nutrients, 11 for nitrogen, 7 for water, 11 for interacting drivers, and 33 for other GCDs

Across all treatment-control comparisons, GCDs increased mean ANPP by $28 \%(t=7.014 ; p<0.001$; Fig. $1 c)$ but did not affect the temporal variability of ANPP ( $t=-1.669 ; p=0.099 ;$ Fig. $1 \mathrm{~d})$. Multiple nutrient additions increased ANPP by $47 \%$ ( $t=6.54 ; p<0.001$; Fig. $1 c)$ but had no effect on temporal variability of ANPP $(t=1.59 ; p=1.121$; Fig. $1 \mathrm{~d})$. Similarly, nitrogen and water additions both increased ANPP by $25 \%$ and $35 \%$, respectively, (nitrogen: $t=3.35 ; p=0.007$; water: $t=3.44 ; p=0.014$; Fig. $1 \mathrm{c}$ ), but neither affected the temporal variability of ANPP (nitrogen: $t=-0.872 ; p=0.400$; water: $t=-1.23, p=0.264$; Fig. $1 \mathrm{~d}$ ). Interacting drivers increased ANPP by $26 \%$ ( $t=3.30 ; p=0.008$ ), but had no effect on the temporal variability of ANPP $(t=1.51 ; p=0.162)$. We found no effect of the amount of nitrogen or water added on mean ANPP and temporal variability ANPP, however, there was greater production response with higher amounts of multiple nutrients added, but no effect on CV of ANPP (ESM Figure S3).

\section{Do abiotic and biotic characteristics alter the effect of GCDs on temporal variability of}

\section{ANPP?}

We found that, together, site MAT, MAP, and evenness explained $45 \%$ of the variation in percent difference of temporal variability of ANPP (adj. $\left.R^{2}=0.446 ; p<0.001\right)$. GCD treatments increased temporal variability of ANPP 
in ecosystems that were drier (partial $R^{2}=0.086 ; p<0.05$ : Fig. 2 c) and colder (partial $R^{2}=0.108 ; p<0.001$; Fig. 2d). Removing the coldest site did not change the relationship between MAT and temporal variability of ANPP (data not shown). In contrast, GCD treatments decreased temporal variability in ANPP at less even sites (partial $R^{2}=0.101 ; p<0.05$; Fig. 2b).

(a) Sp. Richness

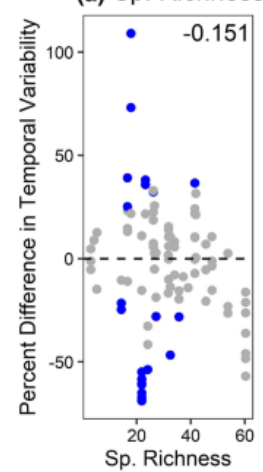

(b) Evenness

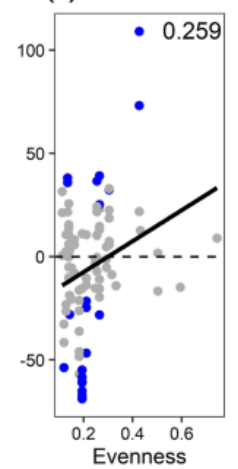

(c) MAP

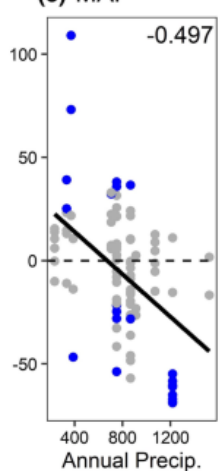

(d) MAT

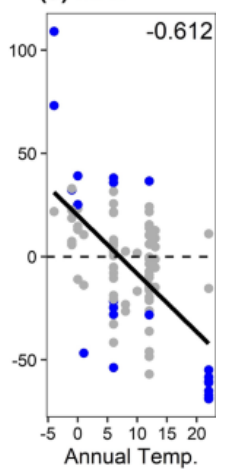

Fig. 2 Correlations of percent differences between treated and control plots temporal variability of ANPP with different biotic a Sp. richness b species evenness (measured using Evar), and abiotic c MAP (mm), d MAT $\left({ }^{\circ} \mathrm{C}\right)$ variables (see text for details). The correlation coefficient, $r$, is shown in the top right, and smoothed lines were included when correlations were significant $(p<0.05)$. Blue points indicate that treatment plots differed significantly from controls. Points above the zero line indicate that treated plots had higher values than the controls and vice versa. Please note two sites have MAT of $12{ }^{\circ} \mathrm{C}$ and two sites have very similar MAP and are difficult to tease apart (369-386). $n=95$

\section{Do GCDs affect sensitivity of ANPP to annual precipitation?}

Overall, GCDs increased sensitivity of ANPP to precipitation (Fig. 3; $t$ value $=4.12 ; p$ value $<0.001$ ). The multinutrient additions increased sensitivity of ANPP to precipitation ( $t$ value $=2.95, p=0.006$ ), but nitrogen ( $t$ value $=1.27, p=0.232)$, water additions ( $t$ value $=-1.89, p=0.107)$ and interacting drivers ( $t$ value $=1.18 ; p=0.265 ;$ Fig. 3 ) had no effect.

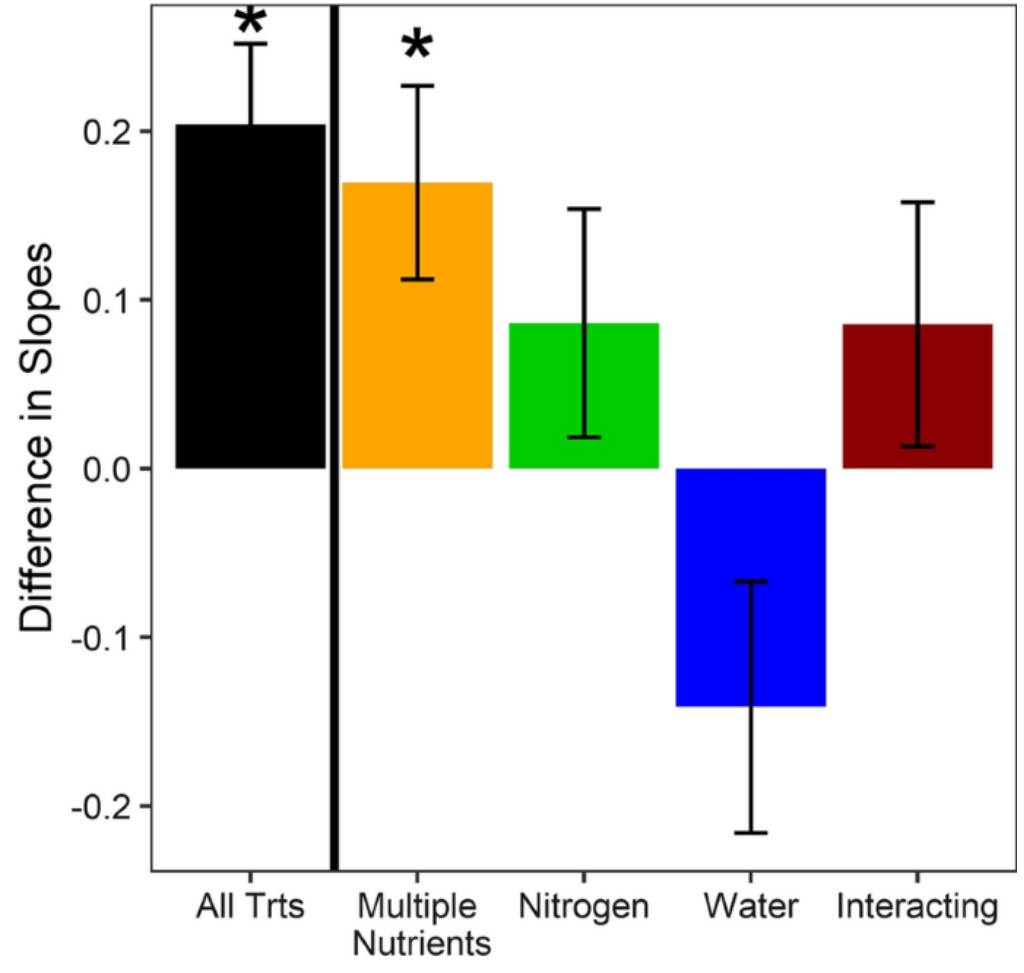


Fig. 3 Effect of GCDs on the sensitivity of ANPP to precipitation (differences in slopes of treated and control plots of the relationship between annual precipitation and ANPP) for all treatments, three different GCDs, and interacting GCDs. An asterisk denotes significant difference from zero at $p<0.05$ ). $\mathrm{n}=95$ for all trts, 33 for multiple nutrients, 11 for nitrogen, 7 for water, and 11 for interacting drivers

\section{Discussion}

The analysis of GCD treatment effects on mean and variability of ANPP across several herbaceous ecosystems revealed that mean ANPP was affected by GCD treatments more often than temporal variability of ANPP. Overall, the GCD treatments studied here increased mean ANPP, but there were no consistent effects of GCD treatments on temporal variability of ANPP. While we found examples of temporal variability increasing and decreasing, most often it did not change. Differential effects of GCDs on temporal variability of ANPP could be explained by several factors. First, sites that were wetter, warmer and had lower evenness became less variable. Second, our results also showed that GCD treatments increased ANPP sensitivity to precipitation. We also found that when studying interacting drivers (e.g. elevated $\mathrm{CO}_{2}$ and nitrogen), their effects were similar to single drivers suggesting multiple drivers are not diminishing nor amplifying one another. Overall, these results demonstrate that site differences, both biotic and abiotic, are important determinants of responses of temporal variability of ANPP to GCDs across ecosystems.

We found general support for our hypothesis that GCD treatments investigated here would increase ANPP. This is not too surprising given that many of the treatments in these experiments were resource additions and mirror other findings (Nowak et al. 2004; Wu et al. 2011; Wilcox et al. 2017; Song et al. 2019). However, although GCD treatments increased ANPP overall, ANPP significantly differed between control and treatment in only $44 \%$ of the comparisons. Treatments that had two or more interacting factors did not result in augmented or diminished effects on ANPP compared with single drivers, which is possible evidence that predicting the effects of multiple interacting GCDs together might be difficult using data from single GCD manipulations alone (Leuzinger et al. 2011).

Contrary to our first hypothesis, we found no overall effect of GCD treatments on temporal variability of ANPP as measured by the coefficient of variation. This result was consistent for the analysis of all GCD treatments and for the multiple nutrient, nitrogen, water, and interacting driver treatments when analyzed separately. This contrasts with findings from some single site studies where temporal variability was influenced by treatments. For example, at Cedar Creek, Minnesota, Hautier et al. (2015) found that GCD treatments increased temporal variability of ANPP and attributed this to species loss. In contrast, at the Kellogg Biological Station, Michigan, Grman et al. (2010) found nitrogen and disturbance decreased variability, which they attributed to species compositional differences. At Lanzhou, China, Niu et al. (2017a, b) reported that greater amounts of $\mathrm{N}$ addition resulted in greater variability of ANPP. In a cross-site study of grassland responses to three years of nutrient additions, temporal variability of ANPP increased (Hautier et al. 2014), which was attributed to nutrient additions weakening biodiversity effects. While we did find examples of temporal variability of ANPP increasing and decreasing in some experiments, overall, we found no systematic response, and overwhelmingly the majority of treatments had no effect on variability. A caveat of our findings is that the majority of our GCD treatments were resource increases and resource reductions may have yielded different results, which demonstrate the need for more long-term resource-reduction experiments, especially drought.

We found evidence for our second hypothesis that biotic site characteristics underlie differential responses of temporal variability of ANPP. Contrary to our hypothesis that sites with more species would have less variable production in response to GCDs, we found higher species richness did not buffer against year-to-year fluctuations of production. Previous studies found that more diverse areas (higher species richness) have more stable production over time (Tilman et al. 2006) and GCD treatments that cause declines in species richness also 
have reduced stability of production over time (Hautier et al. 2015). However, we did find that in less even ecosystems GCD treatments reduced temporal variability of ANPP, highlighting dominance as a potential mechanism of stability (Hallett et al. 2014). GCD treatments, especially nutrient additions, can decrease evenness (Houseman et al. 2008; Avolio et al. 2014) and when evenness is low, production is most likely driven by a few species and perhaps these species are less responsive to GCDs (Lepš et al. 1982; MacGillivray and Grime 1995; Yu et al. 2015).

In addition to evenness, we found abiotic site characteristics drive differential responses of temporal variability of ANPP, further supporting our second hypothesis. Treatments increased temporal variability of ANPP in colder and drier ecosystems and decreased temporal variability of ANPP in wetter and warmer ecosystems. Maximum plant growth rate often limits ANPP, which is evidenced by saturating non-linear relationships between resources and primary productivity (Knapp et al. 2017; Wilcox et al. 2017). In high-resource years at wetter and warmer ecosystems, GCD treatments that increase resources may have minimal impacts on ANPP. This would effectively reduce the year-to-year variability in ANPP in more mesic systems, as we observed here. Alternately, resource-poor ecosystems are often below their productivity potential so that responses in wet years to GCDs are often large. For example, Ladwig et al. (2012) showed that nitrogen addition in a Chihuahuan Desert grassland greatly increased ANPP responses in wet years, but not in dry years, leading to increased variability of ANPP in nitrogen addition plots.

Finally, we found support for our third hypothesis that sensitivity of ANPP to precipitation was increased by GCD treatments, and further, that multiple nutrient additions caused ANPP to be more sensitive to precipitation. Multiple nutrient additions would alleviate many co-limitations on ANPP (Fay et al. 2015), thus making the productivity of an ecosystem more dependent on water as a limiting resource (Huxman et al. 2004; Ladwig et al. 2012). However, we found that water addition had no overall effect on sensitivity to precipitation. The fact that nitrogen additions alone did not affect sensitivity, but multiple nutrients did support prior work indicating that many ecosystems are co-limited by multiple resources (Harpole et al. 2016).

\section{Conclusion}

Understanding variability of ANPP through time is important for the maintaining consistency of ecosystem services, as well as informing about the probability of ecosystems crossing catastrophic thresholds, such as the 1930's Dust Bowl. We found no significant differences in temporal variability of ANPP for $76 \%$ of controltreatment comparisons, and when differences were found, both increases and decreases occurred resulting in no overall effect. Several factors contribute to the contrasting effects of GCDs on temporal variability of ANPP including site differences in biotic and abiotic characteristics as well as altered sensitivity to precipitation. Our results suggest GCDs are more likely to increase temporal variability of ANPP in dry and cool ecosystems and in communities with high evenness that lack a strong dominant species. We suggest that these ecosystems should be a priority for future research and conservation efforts to mitigate increased variability under various global change drivers. Our finding that multiple nutrient additions increased the sensitivity of ANPP to precipitation highlights the need to closely monitor eutrophication rates and their effects, especially when multiple types of nutrient enrichment may occur, such as simultaneous $\mathrm{N}$ and $\mathrm{P}$ fertilization. We conclude that GCDs that increase resources are more likely to affect mean than temporal variability in ANPP, and thus, the impacts of GCDs on reliability of ecosystem production are expected to be minimal relative to the magnitude of change in production.

\section{References}

Andresen LC, Müller C, de Dato G et al (2016) Shifting impacts of climate change: long-term patterns of plant response to elevated CO2, drought, and warming across ecosystems. In: Dumbrell AJ, 
Kordas RL, Woodward G (eds) Advances in Ecological Research. Oxford Academic Press, Oxford, UK, pp 437-473

Avolio ML, Koerner SE, La Pierre KJ et al (2014) Changes in plant community composition, not diversity, during a decade of nitrogen and phosphorus additions drive above-ground productivity in a tallgrass prairie. J Ecol 102:1649-1660. https://doi.org/10.1111/1365-2745.12312

Borer ET, Seabloom EW, Gruner DS et al (2014) Herbivores and nutrients control grassland plant diversity via light limitation. Nature 508:517-520. https://doi.org/10.1038/nature13144

Chamberlain S (2018) rnoaa: "NOAA" Weather Data from R. https://CRAN.Rproject.org/package=rnoaa

Clark JS, Carpenter SR, Barber M et al (2001) Ecological forecasts: an emerging imperative. Science 80(293):657-660. https://doi.org/10.1126/science.293.5530.657

Clements FE (1916) Plant succession; an analysis of the development of vegetation. Carnegie Institue of Washington, Washington

Collins SL, Belnap J, Grimm NB et al (2014) A multiscale, hierarchical model of pulse dynamics in aridland ecosystems. Annu Rev Ecol Evol Syst 45:397-419. https://doi.org/10.1146/annurevecolsys-120213-091650

Daily GC, Polasky S, Goldstein J et al (2009) Ecosystem services in decision making: time to deliver. Front Ecol Environ 7:21-28. https://doi.org/10.1890/080025

Darling ES, Côté IM (2008) Quantifying the evidence for ecological synergies. Ecol Lett 11:12781286. https://doi.org/10.1111/j.1461-0248.2008.01243.x

Elser JJ, Bracken MES, Cleland EE et al (2007) Global analysis of nitrogen and phosphorus limitation of primary producers in freshwater, marine and terrestrial ecosystems. Ecol Lett 10:11351142. https://doi.org/10.1111/j.1461-0248.2007.01113.x

Fay PA, Prober SM, Harpole WS et al (2015) Grassland productivity limited by multiple nutrients. Nat Plants 1:15080. https://doi.org/10.1038/nplants.2015.80

Grman E, Lau JA, Schoolmaster DR, Gross KL (2010) Mechanisms contributing to stability in ecosystem function depend on the environmental context. Ecol Lett 13:14001410. https://doi.org/10.1111/j.1461-0248.2010.01533.x

Gross K, Cardinale BJ, Fox JW et al (2014) Species richness and the temporal stability of biomass production: a new analysis of recent biodiversity experiments. Am Nat 183:112. https://doi.org/10.1086/673915

Hallett LM, Hsu J, Cleland EE et al (2014) Biotic mechanisms of community stability shift along a precipitation gradient. Ecology 95:1693-1700

Hallett LM, Avolio ML, Carroll I et al (2019) codyn: Community Dynamics Metrics. https://CRAN.Rproject.org/package $=$ codyn

Harpole WS, Sullivan LL, Lind EM et al (2016) Addition of multiple limiting resources reduces grassland diversity. Nature 537:93-96. https://doi.org/10.1038/nature19324

Hautier Y, Seabloom EW, Borer ET et al (2014) Eutrophication weakens stabilizing effects of diversity in natural grasslands. Nature 508:521-525. https://doi.org/10.1038/nature13014

Hautier Y, Tilman D, Isbell F et al (2015) Anthropogenic environmental changes affect ecosystem stability via biodiversity. Science 80-(348):336-340

Hector A, Schmid B, Beierkuhnlein C et al (1999) Plant diversity and productivity experiments in European grasslands. Science 80-(286):1123-1127

Hector A, Hautier Y, Saner P et al (2010) General stabilizing effects of plant diversity on grassland productivity through population asynchrony and overyielding. Ecology 91:22132220. https://doi.org/10.1890/09-1162.1 
Hoover DL, Knapp AK, Smith MD (2014) Resistance and resilience of a grassland ecosystem to climate extremes. Ecology 95:2646-2656. https://doi.org/10.1890/13-2186.1

Houseman GR, Mittelbach GG, Reynolds HL, Gross KL (2008) Perturbations alter community convergence, divergence, and formation of multiple community states. Ecology 89:21722180. https://doi.org/10.1890/07-1228.1

Huxman TE, Smith MD, Fay PA et al (2004) Convergence across biomes to common rain use efficiency. Nature 429:651-654. https://doi.org/10.1038/nature02597.1

Isbell F, Craven D, Connolly J et al (2015) Biodiversity increases the resistance of ecosystem productivity to climate extremes. Nature 526:574-577. https://doi.org/10.1038/nature15374

Ives AR, Carpenter SR (2007) Stability and diversity of ecosystems. Science 317:5863. https://doi.org/10.1126/science.1133258

Knapp AK, Smith MD (2001) Variation among biomes in temporal dynamics of aboveground primary production. Science 80-(291):481-484

Knapp AK, Briggs JM, Koelliker JK (2001) Frequency and extent of water limitation to primary production in a mesic temperate grassland. Ecosystems 4:19-

28. https://doi.org/10.1007/s100210000057

Knapp AK, Ciais P, Smith MD (2017) Reconciling inconsistencies in precipitation-productivity relationships: implications for climate change. New Phytol 214:4147. https://doi.org/10.1111/nph.14381

Koerner SE, Avolio ML, La Pierre KJ et al (2016) Nutrient additions cause divergence of tallgrass prairie plant communities resulting in loss of ecosystem stability. J Ecol 104:14781487. https://doi.org/10.1111/1365-2745.12610

Komatsu KJ, Avolio ML, Lemoine NP et al (2019) Global change effects on plant communities are magnified by time and the number of global change factors imposed. Proc Natl Acad Sci 116:17867-17873. https://doi.org/10.1073/pnas.1819027116

La Pierre KJ, Blumenthal DM, Brown CS et al (2016) Drivers of variation in aboveground net primary productivity and plant community composition differ across a broad precipitation gradient. Ecosystems 19:521-533. https://doi.org/10.1007/s10021-015-9949-7

Ladwig LM, Collins SL, Swann AL et al (2012) Above- and belowground responses to nitrogen addition in a Chihuahuan Desert grassland. Oecologia 169:177-185. https://doi.org/10.1007/s00442011-2173-z

Lehman CL, Tilman D (2000) Biodiversity, stability, and productivity in competitive communities. Am Nat 156:534-552. https://doi.org/10.1086/303402

Lepš J, Osbornová-Kosinová J, Rejmánek M (1982) Community stability, complexity and species life history strategies. Vegetatio 50:53-63. https://doi.org/10.1007/BF00120678

Leuzinger S, Luo Y, Beier C et al (2011) Do global change experiments overestimate impacts on terrestrial ecosystems? Trends Ecol Evol 26:236-

241. https://doi.org/10.1016/j.tree.2011.02.011

MacArthur RH (1955) Fluctuations of animal populations and a measure of community stability. Ecology 36:533-536

MacGillivray CW, Grime JP (1995) Testing predictions of the resistance and resilience of vegetation subjected to extreme events. Funct Ecol 9:640-649. https://doi.org/10.1093/imammb/20.4.367

May RM (1973) Stability and complexity in model ecosystems. Princeton University Press, Princeton, N.J.

McNaughton SJ, Oesterheld M, Frank DA, Williams KJ (1989) Ecosystem-level patterns of primary productivity and herbivory in terrestrial habitats. Nature 341:142-144 
Morgan JA, Mosier AR, Milchunas DG et al (2004) CO2 enhances productivity, alters species composition, and reduces digestibility of shortgrass steppe vegetation. Ecol Appl 14:208-219

Morgan JA, LeCain DR, Pendall E et al (2011) C4 grasses prosper as carbon dioxide eliminates desiccation in warmed semi-arid grassland. Nature 476:202205. https://doi.org/10.1038/nature10274

Natali SM, Schuur EAG, Rubin RL (2012) Increased plant productivity in Alaskan tundra as a result of experimental warming of soil and permafrost. J Ecol 100:488498. https://doi.org/10.1111/j.1365-2745.2011.01925.x

Niu D, Yuan X, Cease AJ et al (2017) The impact of nitrogen enrichment on grassland ecosystem stability depends on nitrogen addition level. Sci Total Environ 615:15291538. https://doi.org/10.1016/j.scitotenv.2017.09.318

Niu S, Fu Z, Luo Y et al (2017) Interannual variability of ecosystem carbon exchange: from observation to prediction. Glob Ecol Biogeogr 26:1225-1237. https://doi.org/10.1111/geb.12633

Nowak RS, Ellsworth DS, Smith SD (2004) Functional responses of plants to elevated atmospheric CO2Do photosynthetic and productivity data from FACE experiments support early predictions? New Phytol 162:253-280. https://doi.org/10.1111/j.1469-8137.2004.01033.x

Noy-Meir I (1973) Desert ecosystems: environment and producers. Annu Rev Ecol Syst 4:25-51

Oksanen J, Blanchet FG, Friendly M et al (2019) vegan: Community Ecology Package. https://CRAN.Rproject.org/package=vegan

R Core Team (2019) R: A language and environment for statistical computing. R foundation for statistical computing, Vienna, Austria. https://www.R-project.org/

Rudgers JA, Chung YA, Maurer GE et al (2018) Climate sensitivity functions and net primary production: a framework for incorporating climate mean and variability. Ecology 99:576582. https://doi.org/10.1002/ecy.2136

Rustad L, Campbell J, Marion G et al (2001) A meta-analysis of the response of soil respiration, net nitrogen mineralization, and aboveground plant growth to experimental ecosystem warming. Oecologia 126:543-562. https://doi.org/10.1007/s004420000544

Sala OE, Parton W, Joyce LA, Lauenroth WK (1988) Primary production of the central grassland region of the United States. Ecology 69:40-45. https://doi.org/10.2307/1943158

Sala OE, Lauenroth W, McNaughton SJ et al (1996) Biodiversity and ecosystem functioning in grasslands. In: Mooney HA, Cushman JH, E. M, et al. (eds) functional role of biodiversity: a global perspective. John Wiley and Sons Ltd, New York, NY, pp 129-149

Sala OE, Chapin FS, Armesto JJ et al (2000) Global biodiversity sScenarios for the year 2100. Science 80(287):1770-1775. https://doi.org/10.1126/science.287.5459.1770

Sala OE, Gherardi LA, Reichmann L et al (2012) Legacies of precipitation fluctuations on primary production: theory and data synthesis. Philos Trans R Soc B Biol Sci 367:31353144. https://doi.org/10.1098/rstb.2011.0347

Schimel DS, Braswell BH, Parton WJ (1997) Equilibration of the terrestrial water, nitrogen, and carbon cycles. Proc Natl Acad Sci U S A 94:8280-8283. https://doi.org/10.1073/pnas.94.16.8280

Seddon AWR, Macias-Fauria M, Long PR et al (2016) Sensitivity of global terrestrial ecosystems to climate variability. Nature 531:229-232. https://doi.org/10.1038/nature16986

Smith B, Wilson JB (1996) A consumer's guide to evenness indices. Oikos 76:70-82

Smith MD, La Pierre KJ, Scott P et al (2015) Global environmental change and the nature of aboveground net primary productivity responses: insights from long-term experiments. Oecologia 177:935-947. https://doi.org/10.1007/s00442-015-3230-9 
Song J, Wan S, Piao S et al (2019) A meta-analysis of 1,119 manipulative experiments on terrestrial carbon-cycling responses to global change. Nat Ecol Evol 3:13091320. https://doi.org/10.1038/s41559-019-0958-3

Tilman D, Downing JA (1994) Biodiversity and stability in grasslands. Nature 367:363365. https://doi.org/10.1038/367363a0

Tilman D, Reich PB, Knops JMH (2006) Biodiversity and ecosystem stability in a decade-long grassland experiment. Nature 441:629-632. https://doi.org/10.1038/nature04742

Tilman D, Reich PB, Isbell F (2012) Biodiversity impacts ecosystem productivity as much as resources, disturbance, or herbivory. Proc Natl Acad Sci 109:1039410397. https://doi.org/10.1073/pnas.1208240109

Venables WN, Ripley BD (2002) Modern applied statistics with S. Springer, New York

Vitousek PM, Mooney HA, Lubchenco J, Melillo JM (1997) Human domination of Earth's ecosystems. Science 80-(277):494-499. https://doi.org/10.1126/science.277.5325.494

Wilcox KR, Blair JM, Smith MD, Knapp AK (2016) Does ecosystem sensitivity to precipitation at the sitelevel conform to regional-scale predictions? Ecology 97:561-568. https://doi.org/10.1890/151437.1

Wilcox KR, Shi Z, Gherardi LA et al (2017) Asymmetric responses of primary productivity to precipitation extremes: a synthesis of grassland precipitation manipulation experiments. Glob Chang Biol 23:4376-4385. https://doi.org/10.1111/gcb.13706

Wu Z, Dijkstra P, Koch GW et al (2011) Responses of terrestrial ecosystems to temperature and precipitation change: a meta-analysis of experimental manipulation. Glob Chang Biol 17:927942. https://doi.org/10.1111/j.1365-2486.2010.02302.x

Yu Q, Wilcox K, La Pierre K et al (2015) Stoichiometric homeostasis predicts plant species dominance, temopral stability and respnses to global change. Ecology 96:23282335. https://doi.org/10.1890/14-1897.1

Zhang D (2018) rsq: R-Squared and related measures. https://CRAN.R-project.org/package=rsq 